Article

\title{
Synthesis and Sintering of ZnO Nanopowders
}

\author{
Anne Aimable ${ }^{1, *}$, Hervé Goure Doubi ${ }^{1}$, Michael Stuer ${ }^{2}$, Zhe Zhao ${ }^{3}$ and Paul Bowen ${ }^{2}$ \\ 1 SPCTS, UMR CNRS-Université de Limoges 7315, Centre Européen de la Céramique, Limoges 87068, France; \\ goure_herve2610@yahoo.fr \\ 2 Powder Technology Laboratory, Material Science Institute, Swiss Federal Institute of Technology, \\ Lausanne 1015, Switzerland; michael.stuer@cartier.com (M.S.); paul.bowen@epfl.ch (P.B.) \\ 3 Department of Materials Science and Engineering, KTH Royal Institute of Technology, \\ Stockholm 10044, Sweden; zhezhao@kth.se \\ * Correspondence: anne.aimable@unilim.fr; Tel.: +33-587-502-368
}

Academic Editor: Paolo Veronesi

Received: 14 April 2017; Accepted: 22 May 2017; Published: 30 May 2017

\begin{abstract}
Nanopowders are continuously under investigation as they open new perspectives in numerous fields. There are two main challenges to stimulating their development: sufficient low-cost, high throughput synthesis methods which lead to a production with well-defined and reproducible properties; and for ceramics specifically, the conservation of the powders' nanostructure after sintering. In this context, this paper presents the synthesis of a pure nanosized powder of $\mathrm{ZnO}$ $\left(\mathrm{dv}_{50} \sim 60 \mathrm{~nm}\right.$, easily redispersable) by using a continuous Segmented Flow Tubular Reactor (SFTR), which has previously shown its versatility and its robustness, ensuring a high powder quality and reproducibility over time. A higher scale of production can be achieved based on a "scale-out" concept by replicating the tubular reactors. The sinterability of $\mathrm{ZnO}$ nanopowders synthesized by the SFTR was studied, by natural sintering at $900^{\circ} \mathrm{C}$ and $1100^{\circ} \mathrm{C}$, and Spark Plasma Sintering (SPS) at $900{ }^{\circ} \mathrm{C}$. The performance of the synthesized nanopowder was compared to a commercial $\mathrm{ZnO}$ nanopowder of high quality. The samples obtained from the synthesized nanopowder could not be densified at low temperature by traditional sintering, whereas SPS led to a fully dense material after only $5 \mathrm{~min}$ at $900{ }^{\circ} \mathrm{C}$, while also limiting the grain growth, thus leading to a nanostructured material.
\end{abstract}

Keywords: ZnO; ceramic nanopowders; Segmented Flow Tubular Reactor (SFTR); Spark Plasma Sintering (SPS)

\section{Introduction}

Nanopowders with a good control on particle size distribution and particle morphology have attracted much interest in the ceramic community, where better performances (optical properties, catalytic properties, mechanical properties, hardness ... ) can be expected from finer grain sizes in dense and nanostructured materials. Since the 1980s, when the concept of colloidal processing of ceramics first appeared, the reliability of ceramics shaping processes has improved through a better control of the suspension parameters, such as its rheological behavior, based on the manipulation of the interparticle forces [1-4]. Most of the colloidal processes are based on the use of highly concentrated ceramic suspensions in order to reach the highest green density and finally the best properties after sintering. However, nanopowders synthesis still suffers from insufficient methods, leading to a low-cost production with well-defined properties. Another limitation for using nanopowders in ceramic processing is the sintering process, which usually needs high temperatures and long cycles to fully-densify ceramic powders. This process leads to grain growth, which is very difficult to avoid due to grain boundary motion and Ostwald ripening [5]. Therefore, strong efforts have been put forth to develop more efficient and reliable synthesis processes, as well as new sintering techniques to limit grain growth and conserve "nanoscale" properties. 
In this context this paper presents a complete route for the preparation of dense and nanostructured $\mathrm{ZnO}$ ceramics, through a fine control from the nanopowder properties to the final sintering step. Zinc oxide is a material which has a wide range of applications in ceramics, coatings, and electronic devices. This II-IV semiconductor presents a wide band-gap ( $3.37 \mathrm{eV}$ at room temperature), and a large exciton binding energy $(60 \mathrm{meV})$, and is, therefore, one of the most promising candidates for room temperature UV lasers and short-wavelength optoelectronic devices. Some detailed reviews have been published previously, dedicated to $\mathrm{ZnO}$ synthesis [6], electronic properties [7], varistor applications [8], quantum dots [9] and photonic devices [10], all of which show the constant interest of scientists wanting to improve its properties in various fields [11].

$\mathrm{ZnO}$ sintering mechanisms were extensively studied in the 1960s [12-14]; different groups conducted sintering experiments in air and concluded that the densification process of pure submicronic $\mathrm{ZnO}$ powders is essentially completed in about $1 \mathrm{~h}$ even at a low temperature of $900{ }^{\circ} \mathrm{C}$, with a relative density of around $98 \%$ [15]. However, grain growth was important, leading to final grain sizes between 3-50 $\mu \mathrm{m}$, depending on sintering time and temperature. It was determined that the grain growth process followed a standard phenomenological kinetic grain growth, controlled by the diffusion of zinc ions within the structure [15]. For applications as a varistor, the $\mathrm{ZnO}$ microstructure needs to exhibit the finest microstructure, in order to present a higher number of active grains and grain boundaries [16]. Some strategies, such as low-temperature sintering (below $950^{\circ} \mathrm{C}$ ) [17], or two-step sintering [18] were investigated in more recent years. Grain growth could be successfully limited to below $2 \mu \mathrm{m}$ using this last method, but the sintering cycles were long (several days). Thus Spark Plasma Sintering (SPS) was used for ZnO nanopowders. SPS is a recent advanced pressure and field assisted sintering technique allowing lower sintering temperatures in very fast times (a few minutes) $[19,20]$. Instead of using an external heat source, pulsed current passes through the electrically conducting pressure dyes, thereby generating the sintering temperature [21-23]. SPS has been used to generate dense ceramics with minimum grain growth [19] for many applications [23], including electroceramics [24,25], composites [26,27], bioceramics [28], thermoelectric materials [29], and transparent polycrystalline alumina (PCA) [30]. Only a few publications present SPS sintering of $\mathrm{ZnO}$ nanopowders, even though there is great potential in this technique. For example, nano-sized $\mathrm{ZnO}$ doped powder synthesized by coprecipitation could be sintered by SPS at low temperature $\left(600{ }^{\circ} \mathrm{C}, 250 \mathrm{MPa}\right)$ which leads to small grain sizes $(300-600 \mathrm{~nm})$, and thus, higher performances for varistor applications [31]. For non-doped $\mathrm{ZnO}$ nanopowder a higher temperature is necessary, and translucent $\mathrm{ZnO}$ ceramics could be obtained from $\mathrm{ZnO}$ nanopowders calcinated at $600{ }^{\circ} \mathrm{C}$ during $2 \mathrm{~h}$ followed by SPS sintering ( $\left.10 \mathrm{~min}, 850{ }^{\circ} \mathrm{C}, 80 \mathrm{MPa}\right)$ [32].

In this paper $\mathrm{ZnO}$ was synthesized by precipitation in mild hydrothermal conditions $\left(90^{\circ} \mathrm{C}\right)$ using a tubular reactor: the Segmented Flow Tubular Reactor (SFTR) [33,34]. The SFTR has been developed to overcome the problems of powder production scale-up. By generating identical micro-reactors that facilitate a homogeneous mixing of the reactants, poor mixing and inhomogeneous reaction conditions are thus avoided. This process has proven its versatility and its robustness through the preparation of several different products $\left(\mathrm{CaCO}_{3}[35], \mathrm{BaTiO}_{3}[36]\right.$, and various oxalates $\left.[37,38]\right)$ ensuring a high powder quality (chemical and phase composition, particle size, and shape) and reproducibility over time. The transfer of the laboratory conditions to an industrial scale of production can be easily achieved by multiplying the number of individual tubular reactors running in parallel一that is to say, to "scale-out" rather than "scale-up" [39-41].

Finally the sinterability of $\mathrm{ZnO}$ nanopowders synthesized by the SFTR was studied, through conventional sintering at $900{ }^{\circ} \mathrm{C}$ and $1100{ }^{\circ} \mathrm{C}$, and Spark Plasma Sintering (SPS) at $900{ }^{\circ} \mathrm{C}$. The performances of the synthesized nanopowder were compared to a commercial $\mathrm{ZnO}$ nanopowder from Nabond Technologie Co., one of the best available in the market in terms of purity and granulometry. 


\section{Materials and Methods}

\subsection{ZnO Nanopowders}

$\mathrm{ZnO}$ nanopowder was prepared by precipitation in mild-hydrothermal conditions using a continuous reactor: the Segmented Flow Tubular Reactor (SFTR). The details of the synthesis have been given in a previous publication [42], thus only a brief description is given here (Figure 1). The SFTR has three distinct zones: a micromixer, a segmenter, and a tubular reactor placed in a thermostatic bath, here set at $90{ }^{\circ} \mathrm{C}$. The reactants in the solution pass through the micromixer where initial supersaturation is rapidly created with a mixing time of around 10 milliseconds [41]. The mixed reactants are then segmented by an immiscible solvent, here dodecane. The small suspension volumes created $\left(\sim 0.2 \mathrm{~cm}^{3}\right)$ provide identical ageing conditions, which leads to homogenous growth throughout the residence time. For the current reaction, relatively short residence times of 10 min were used. After the tubular reactor, a heat-exchanger is used to stop the reaction, and cool down the reacting mixture to room temperature. The separation of the aqueous suspension and the immiscible fluid is then carried out in a decanting unit. The powder in the aqueous phase is collected, while the immiscible fluid is recycled for environmental and cost considerations.

The reactants used for the precipitation were zinc nitrate (Solution 1) and sodium hydroxide aqueous solutions (Solution 2). ZnO was synthesized according to the following reaction (Equation (1)).

$$
\mathrm{Zn}^{2+}(\mathrm{aq})+2 \mathrm{HO}^{-}(\mathrm{aq}) \rightarrow \mathrm{ZnO}(\mathrm{s})+\mathrm{H}_{2} \mathrm{O}
$$

The $\mathrm{Zn}$ solution at $0.10 \mathrm{M}$ was made by dissolving $\mathrm{Zn}\left(\mathrm{NO}_{3}\right)_{2}, 6 \mathrm{H}_{2} \mathrm{O}$ in ultrapure water. The $\mathrm{NaOH}$ solution at $0.11 \mathrm{M}$ was made by diluting a titrated solution $\mathrm{NaOH} 1 \mathrm{M}$ in ultrapure water. Poly(acrylic acid) (PAA Mw 2000) at 0.05 wt \% was used as a dispersant in the $\mathrm{NaOH}$ reaction solution to decrease the degree of agglomeration of the synthesized nanopowders [41,43]. The collected powder was washed with ultrapure water four times, and then filtered and dried for $24 \mathrm{~h}$ at $70{ }^{\circ} \mathrm{C}$. The dried powder was used without further treatment.

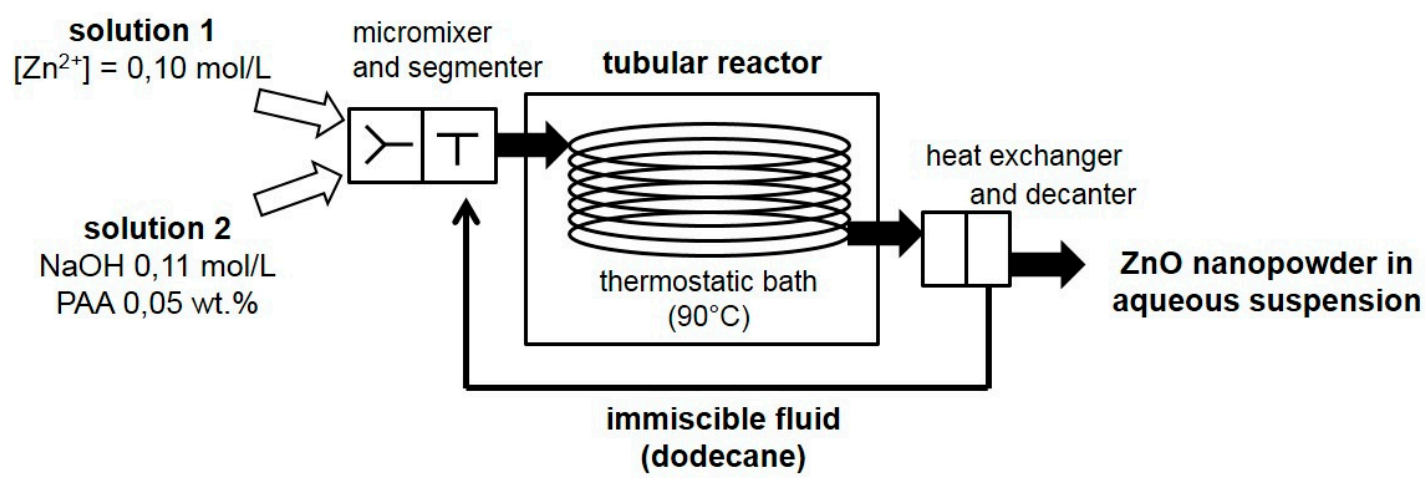

Figure 1. Schematic view of the Segmented Flow Tubular Reactor (SFTR).

The performances of the SFTR ZnO nanopowder were compared to a commercial nanopowder of high quality from Nabond Technologies Co. The specifications given by the provider are $20 \mathrm{~nm}$ in size, $\mathrm{S}_{\mathrm{BET}}>60 \mathrm{~m}^{2} / \mathrm{g}$, and a high purity (99\%). After particle size analysis, an attrition milling was performed in order to eliminate the agglomerates observed. Thirty grams of powder were added to a $500 \mathrm{~mL}$ attrition container, with $50 \mathrm{~mL}$ of water containing a dispersant $(0.1 \mathrm{wt} \%$ of Polyacrylic acid (PAA) $\mathrm{Mw}=2000$ at $\mathrm{pH} 10$ using $\mathrm{NH}_{4} \mathrm{OH}$ ), and $400 \mathrm{~g}$ of beads (1.25 mm zirconia beads). The attrition milling was performed for $1 \mathrm{~h}$ at $1500 \mathrm{rpm}$. The suspension was then filtered on a $1 \mathrm{~mm}$ mesh to separate the milling media, and dried in an oven for $24 \mathrm{~h}$ at $70{ }^{\circ} \mathrm{C}$ to recover the powder. 


\subsection{Sintering Procedure}

Both $\mathrm{ZnO}$ nanopowders-Nabond and SFTR-were sintered following a conventional procedure. The samples were prepared by loading 1.0 gram of powder into a matrix (internal diameter: $13 \mathrm{~mm}$ ) and pressed at $15 \mathrm{kN}$ with a uniaxial pressing apparatus (Schenck, Darmstadt, Germany, MTS Renew). Green bodies were placed in a conventional oven (Nabertherm, New Castle, DE, USA) and heated in air at $5{ }^{\circ} \mathrm{C} / \mathrm{min}$, with a debinding step of $2 \mathrm{~h}$ at $500^{\circ} \mathrm{C}$ in order to remove the organic additives (added during synthesis for the SFTR powder, or during attrition milling for Nabond powder). Two sintering temperatures were studied: $900{ }^{\circ} \mathrm{C}$ and $1100{ }^{\circ} \mathrm{C}$, as well as two sintering times: $2 \mathrm{~h}$, and $4 \mathrm{~h}$.

Both $\mathrm{ZnO}$ nanopowders-Nabond and SFTR powders-were also sintered by Spark Plasma Sintering (SPS) (Dr. Sinter 2050, Sumitomo Coal Mining Co., Tokyo, Japan). They were previously heat-treated at $500{ }^{\circ} \mathrm{C}$ to remove the organic species (heating rate: $5{ }^{\circ} \mathrm{C} / \mathrm{min}$, dwell: $2 \mathrm{~h}$, in air). Then $1.0 \mathrm{~g}$ of powder was loaded into a graphite dye (internal diameter: $12 \mathrm{~mm}$ ), the internal surface of which was covered with a graphite fiber sheet to avoid direct contact between the powder and the graphite die. The sintering temperature was measured by an optical pyrometer focused on a small cavity in the graphite die (the distance between powder and cavity bottom was $5 \mathrm{~mm}$ ). For maximum reproducibility, the sintering temperature and pressure were controlled by automatic controller units. The sintering temperature $900{ }^{\circ} \mathrm{C}$ was reached in $3 \mathrm{~min}$, and $1100^{\circ} \mathrm{C}$ in $5 \mathrm{~min}$, after a dwell of $3 \mathrm{~min}$ at $600{ }^{\circ} \mathrm{C}$ (heating rate $100{ }^{\circ} \mathrm{C} / \mathrm{min}$ ), and maintained for $5 \mathrm{~min}$. The uniaxial pressure was raised to the final sintering pressure of $100 \mathrm{MPa}$ during the first $2 \mathrm{~min}$, and maintained at $100 \mathrm{MPa}$ over the whole process. The cooling step was very fast, so that three samples per hour could be easily sintered.

The sintering procedures (natural sintering and SPS) are presented in Figure 2.

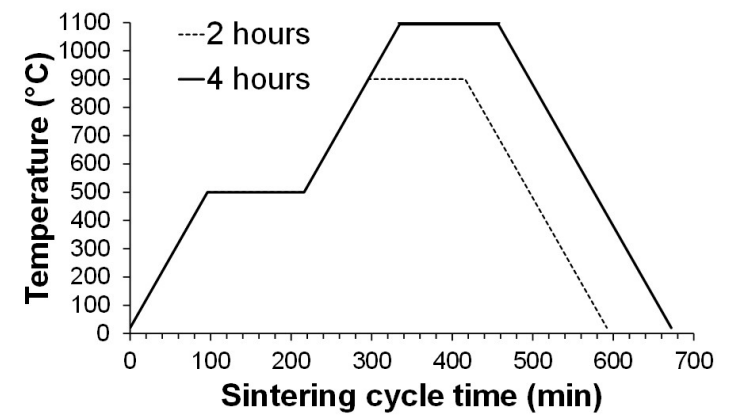

(a) Natural sintering procedure

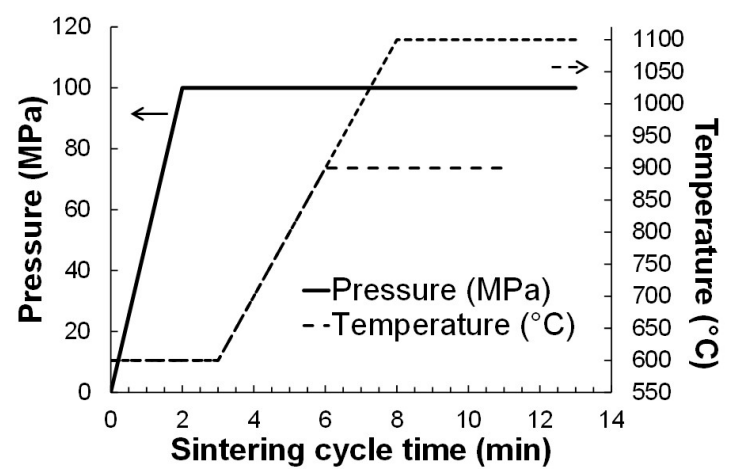

(b) SPS sintering procedure

Figure 2. Sintering procedure for $\mathrm{ZnO}$ nanopowders (a) by the conventional way, and (b) by Spark Plasma Sintering (SPS).

\subsection{Characterization Methods}

$\mathrm{ZnO}$ nanopowders as well as sintered materials were characterized by $\mathrm{X}$-ray diffraction $(\mathrm{XRD}, \mathrm{D} 8$ Advance Bruker, Billerica, MA, USA, $\mathrm{Cu}-\mathrm{K} \alpha$ radiation). XRD peak broadening was used to determine the size of the primary crystallite in the powders using the Scherrer equation (Equation (2)). The instrumental broadening was determined using alumina with a large crystal size $(>1 \mu \mathrm{m})$. Therefore:

$$
d_{\mathrm{XRD}}=\frac{\mathrm{K} \lambda_{\mathrm{X}}}{\beta_{\mathrm{X} p} \cos \theta}
$$

where $\mathrm{K}$ is equal to 0.9 [44]; $\lambda_{\mathrm{X}}$ is the $\mathrm{X}$-ray wavelenght; $\beta_{\mathrm{Xp}}$ is the integral breadth of the material, calculated using $\beta_{X p}=\sqrt{\beta^{2}-\beta_{\text {alumina }}^{2}}$; and $\beta$ the integral breadth is the ratio of the area and the height of the diffraction peak. 
The particle size distribution of the powders was collected using a centrifugal method (CPS, Disc Centrifuge Model DC 24,000) [45]. The span of the particle size disctribution (PSD) was calculated from Equation (3), which gives an indication of the width of the PSD:

$$
\operatorname{span}=\frac{d_{v 90}-d_{v 10}}{d_{v 50}}
$$

Brunauer-Emmett-Teller (BET) specific surface areas $\mathrm{S}_{\mathrm{BET}}\left(\mathrm{m}^{2} / \mathrm{g}\right)$ were estimated from $\mathrm{N}_{2}$ adsorption isotherms (Micromeritics Gemini 2375). The size of the primary particles, $d_{\text {BET }}(n m)$, were calculated by assuming spherical monodisperse particles (Equation (4)), with $\rho=5.606 \mathrm{~g} / \mathrm{cm}^{3}$ being the density of the material:

$$
d_{B E T}=\frac{6000}{\mathrm{~S}_{\mathrm{BET}} \cdot \rho}
$$

Agglomeration factor was estimated by using Equation (5):

$$
F_{a g g}=\frac{d_{v 50}}{d_{B E T}}
$$

Powder morphology was observed by scanning electron microscopy (SEM, Quanta 450 FEG, FEI microscope, Hillsboro, OR, United States). SEM samples were prepared by dispersing the powder in ethanol. One drop of the suspension was then deposited on an aluminum support and dried in air.

The microstructures of the sintered samples were observed on carbon-coated fracture surfaces by SEM (FEG JSM-7000, JEOL, Tokyo, Japan). The mean grains size was calculated using the intercept method on 40 grains.

Dilatometry was performed using TMA Evolution instrument, from Setaram, Caluire-et-Cuire, France. The samples were heated at $1200{ }^{\circ} \mathrm{C}$ with a heating rate of $10^{\circ} \mathrm{C} / \mathrm{min}$.

Densities were measured using the Archimedes method in isopropanol $\left(\rho_{\text {isopropanol }}=0.786 \mathrm{~g} / \mathrm{cm}^{3}\right)$. The relative densities were calculated using $5.606 \mathrm{~g} / \mathrm{cm}^{3}$ for dense $\mathrm{ZnO}$.

\section{Results}

\subsection{Characterization of $\mathrm{ZnO}$ Nanopowders}

$\mathrm{ZnO}$ nanopowders were characterized and the results are reported in Table 1. The specific surface area of Nabond powder is $16.3 \mathrm{~m}^{2} / \mathrm{g}$ which is below the expected value announced by the provider $\left(>60 \mathrm{~m}^{2} / \mathrm{g}\right.$ ), leading to an equivalent BET diameter of $66 \mathrm{~nm}$ (expected value $20 \mathrm{~nm}$ ). The powders synthesized using the SFTR process present a high specific surface area of $78.2 \mathrm{~m}^{2} / \mathrm{g}$, and thus a smaller equivalent BET diameter of $14 \mathrm{~nm}$.

Table 1. Comparison of ZnO nanopowders properties: Brunauer-Emmett-Teller (BET), X-ray diffraction (XRD) and granulometry.

\begin{tabular}{ccccccccc}
\hline- & $\mathbf{S}_{\text {BET }}$ & $\mathbf{d}_{\text {BET }}$ & $\mathbf{d}_{\mathbf{X R D}}$ & $\mathbf{d}_{\mathbf{v} 10}$ & $\mathbf{d}_{\mathbf{v} 50}$ & $\mathbf{d}_{\mathbf{v 9 0}}$ & Span & $\mathbf{F}_{\mathbf{a g g}}$ \\
\hline- & $\left(\mathrm{m}^{2} / \mathrm{g}\right)$ & $(\mathrm{nm})$ & $(\mathrm{nm})$ & $(\mathrm{nm})$ & $(\mathrm{nm})$ & $(\mathrm{nm})$ & - & - \\
SFTR powder & 78.2 & 14 & 24 & 42 & 63 & 85 & 0.68 & 4.5 \\
Nabond powder & 16.3 & 66 & 41 & 131 & 250 & 853 & 2.89 & 3.8 \\
Nabond after attrition & 23.8 & 45 & 41 & 102 & 248 & 415 & 1.26 & 5.5 \\
\hline
\end{tabular}

Both powders show a well-defined diffractogram matching the $\mathrm{ZnO}$ pattern of wurtzite (ICDD 075-0576) (Figure 3). They are pure and well-crystallized, with relatively broad XRD peaks, indicating the presence of nanodomains. Their respective crystallite size could be calculated from the (100) reflection (at $31.8^{\circ}$ ) and are $41 \mathrm{~nm}$ for Nabond, and $24 \mathrm{~nm}$ for SFTR, in a range close to the value calculated by the BET method. 


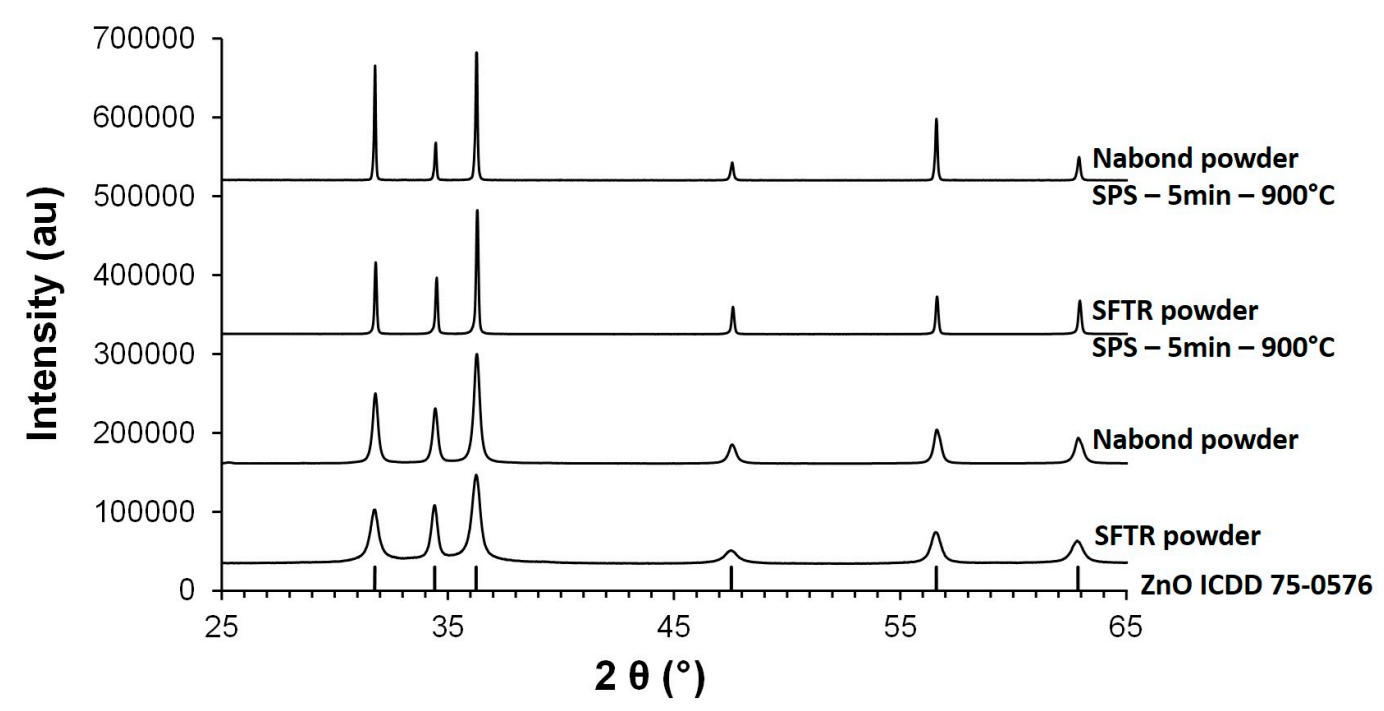

Figure 3. XRD patterns of $\mathrm{ZnO}$ nanopowder synthesized using the SFTR process, commercial Nabond nanopowder, and after sintering by Spark Plasma Sintering for $5 \mathrm{~min}$ at $900{ }^{\circ} \mathrm{C}$.

The particle size distribution of $\mathrm{ZnO}$ nanopowders was measured by a centrifugal method (CPS) (Figure 4). The $\mathrm{d}_{\mathrm{v} 10}, \mathrm{~d}_{\mathrm{v} 50}$ and $\mathrm{d}_{\mathrm{v} 90}$ of the particle size distribution are reported in Table 1. The SFTR powder is a well-dispersable powder with a low degree of agglomeration and a very low median size $d_{v 50}=63 \mathrm{~nm}$. The span of the distribution is also very low (0.68). Nabond powder presents a higher particle size with $\mathrm{d}_{\mathrm{v} 50}=249 \mathrm{~nm}$, and presents a significant tail of agglomerates between 0.5 and $1.0 \mu \mathrm{m}$, leading to a higher span of 2.89. This tail of agglomerates was significantly reduced by an attrition milling, the median size remaining constant at $248 \mathrm{~nm}$.

The morphology of the nanopowders is presented in Figure 5. Commercial Nabond nanopowder is made of particles of $100-200 \mathrm{~nm}$, most of them are equiaxed and a small number are slightly elongated. The precipitated SFTR powder is composed of roundish particles of 50-70 nm, which is in good accordance with the granulometry measurement.

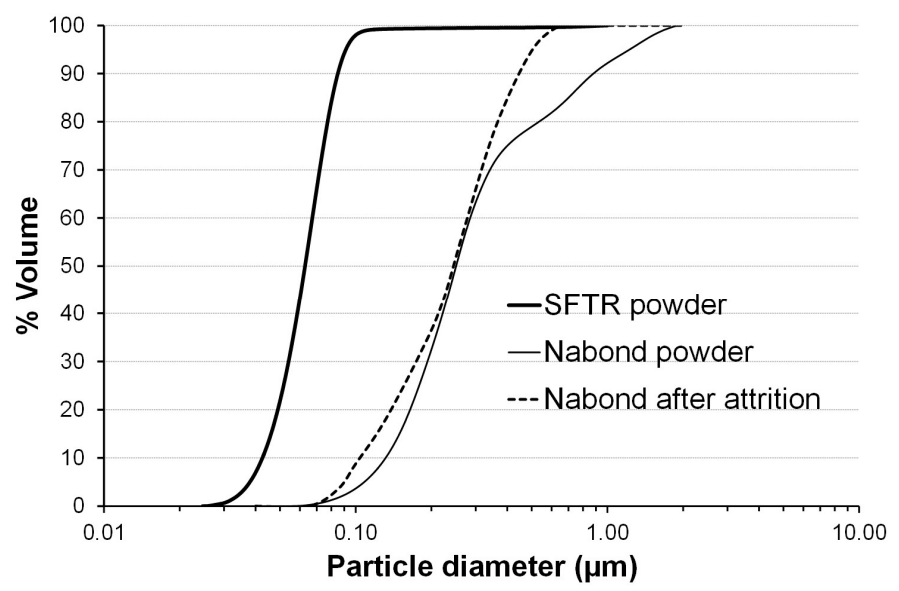

Figure 4. Particle size distribution of ZnO nanopowders synthesized using the SFTR process, and commercial Nabond, as received, and after an attrition treatment. 


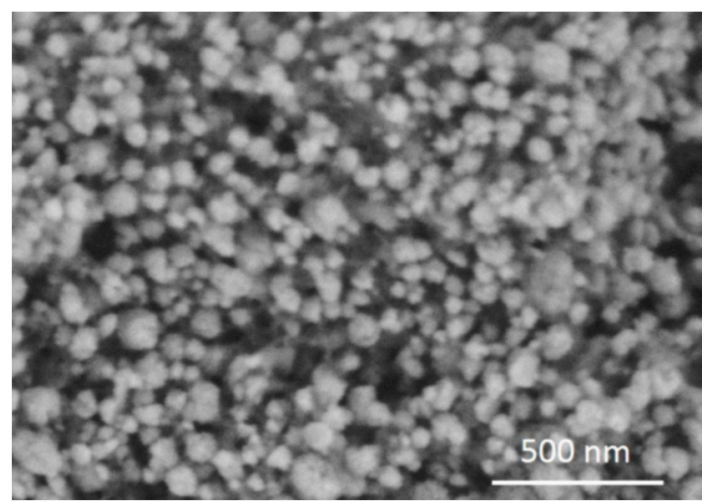

(a)

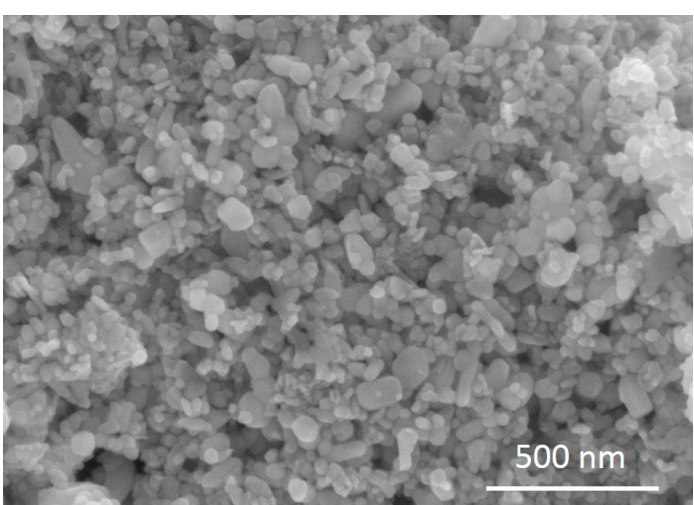

(b)

Figure 5. SEM micrographs of (a) ZnO nanopowder synthesized using the SFTR process, and (b) commercial Nabond nanopowder.

\subsection{Sintering Behavior of $\mathrm{ZnO}$ Nanopowders}

The linear shrinkage behavior of $\mathrm{ZnO}$ during natural sintering is deduced from dilatometry measurements. The linear shrinkage during Spark Plasma Sintering was obtained from continuous measurement of the sample positioning in the apparatus. Both are presented in Figure 6. SFTR powder undergoes a high linear shrinkage under a natural thermal treatment and does not attain a complete shrinkage at $1200{ }^{\circ} \mathrm{C}$; however, this powder was very difficult to prepare because of the very small particle size. Even if this result is taken with caution, though, it still allows for a comparison with Nabond nanopowder, which shows a complete shrinkage at $1100{ }^{\circ} \mathrm{C}$. During SPS treatment, for both powders, linear shrinkage increases until the temperature reaches $900{ }^{\circ} \mathrm{C}$, and then remains stable above $900{ }^{\circ} \mathrm{C}$, which indicates that complete densification should be attained at $900{ }^{\circ} \mathrm{C}$ by SPS.

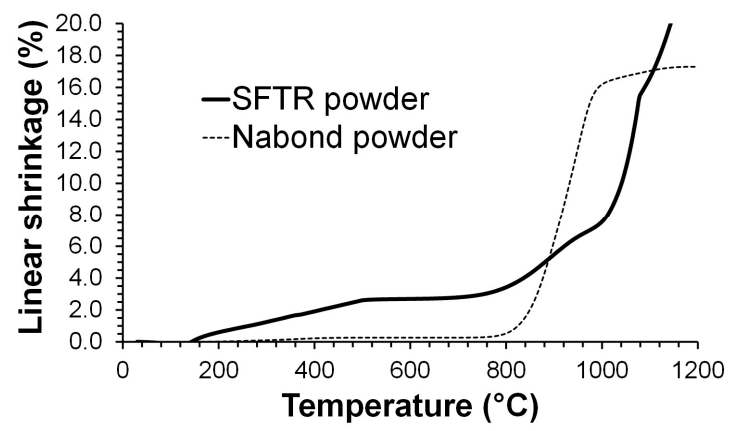

(a) Natural sintering

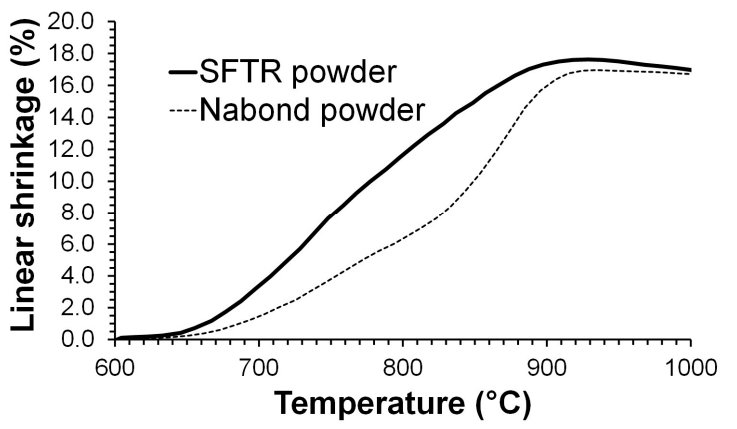

(b) SPS sintering

Figure 6. Linear shrinkage of $\mathrm{ZnO}$ nanopowders (a) by traditional sintering, and (b) by Spark Plasma Sintering.

The relative densities of the different samples after sintering are presented in Table 2 . The relative densities of the green bodies are $44 \%$ and $52 \%$ for SFTR and Nabond samples respectively. Lower green density is obtained with the SFTR powder because its particle size is below $100 \mathrm{~nm}$. Natural sintering of SFTR powder at $900{ }^{\circ} \mathrm{C}$ leads to a small increase of density from $49.2 \%$ after $2 \mathrm{~h}$, to $51.3 \%$, after $4 \mathrm{~h}$. Natural sintering at $1100{ }^{\circ} \mathrm{C}$ does not allow for complete densification as the density is only $60.0 \%$ after $2 \mathrm{~h}$, and $64.7 \%$ after $4 \mathrm{~h}$, which could be expected from the dilatometry measurement. The microstructures of the samples sintered at $900{ }^{\circ} \mathrm{C}$ and $1100{ }^{\circ} \mathrm{C}$ during $2 \mathrm{~h}$ are presented in Figure $7 \mathrm{a}, \mathrm{c}$ respectively. The mean grain size remains close to the original powder grain size at $900{ }^{\circ} \mathrm{C}$, with the grain growth remaining low, and the microstructure being highly porous. The mean grain size after natural sintering at $1100{ }^{\circ} \mathrm{C}$ for $2 \mathrm{~h}$ is $1.2 \mu \mathrm{m} \pm 0.3 \mu \mathrm{m}$, and the microstructure is still highly porous. 
Table 2. Relative densities of $\mathrm{ZnO}$ samples from synthesized nanopowder using the SFTR process, and commercial Nabond, by natural sintering and SPS.

\begin{tabular}{ccccccc}
\hline & \multicolumn{5}{c}{ Relative Density (\%) } \\
\cline { 2 - 7 }- & Green Body & Natural Sintering & SPS Sintering \\
\cline { 2 - 7 } & - & $900{ }^{\circ} \mathrm{C}$ & $1100{ }^{\circ} \mathrm{C}$ & $900{ }^{\circ} \mathrm{C}$ \\
SFTR powder & - & $2 \mathrm{~h}$ & $4 \mathrm{~h}$ & $2 \mathrm{~h}$ & $4 \mathrm{~h}$ & $5 \mathrm{~min}$ \\
Nabond powder & 54.0 & 49.2 & 51.3 & 60.0 & 64.7 & 99.5 \\
\hline
\end{tabular}

Natural sintering of Nabond powder at $900{ }^{\circ} \mathrm{C}$ leads to relative densities of $74.6 \%$ after $2 \mathrm{~h}$, and $79.7 \%$ after $4 \mathrm{~h}$. Sintering at $1100{ }^{\circ} \mathrm{C}$ leads to a relative density of $96.9 \%$ after $2 \mathrm{~h}$ and $98.0 \%$ after $4 \mathrm{~h}$. Therefore, a minimal temperature of $1100{ }^{\circ} \mathrm{C}$ is needed to get a fully-dense material from this $\mathrm{ZnO}$ nanopowder in a traditional oven, as reported previously by Gupta et al. [36], and in accordance with dilatometry measurement. The microstructures of the sample sintered at $900{ }^{\circ} \mathrm{C}$ and $1100{ }^{\circ} \mathrm{C}$ for $2 \mathrm{~h}$ are presented in Figure $7 \mathrm{~b}, \mathrm{~d}$ respectively. Grain growth is small at $900^{\circ} \mathrm{C}$ as the mean grain size is $0.48 \mu \mathrm{m} \pm 0.14 \mu \mathrm{m}$, but important at $1100^{\circ} \mathrm{C}$, because the mean grain size is $3.3 \mu \mathrm{m} \pm 1.4 \mu \mathrm{m}$. Some grains are elongated, and no more porosity is observed at $1100^{\circ} \mathrm{C}$. This grain growth is similar to previous results reported in the literature by different authors [36-38].

Spark Plasma Sintering (SPS) allows $\mathrm{ZnO}$ densification at a lower temperature of $900{ }^{\circ} \mathrm{C}$. After an SPS treatment of $5 \mathrm{~min}$, the $\mathrm{ZnO}$ nanopowder synthesized by the SFTR method is fully dense, with a relative density of $99.5 \%$. The microstructure of this sample is presented in Figure $7 \mathrm{e}$, showing grain sizes in the nanometric range, with a mean grain size of $0.24 \mu \mathrm{m} \pm 0.08 \mu \mathrm{m}$, and a regular morphology. SPS thus densifies and limits grain growth, leading to a fine grain size and a narrow grain size distribution. For the Nabond nanopowder, densification was complete at $900{ }^{\circ} \mathrm{C}$ by SPS but with a lower final density of $95.1 \%$ than the $99.5 \%$ observed for the SFTR powder. The grain growth remained low, as the mean grain size is $1.0 \mu \mathrm{m} \pm 0.5 \mu \mathrm{m}$. Thus, the same grain growth factor of around 4 was obtained with both powders. The grain size distribution is somewhat broader than for the SFTR sample, and some elongated grains are also obtained, which is attributable to the initial characteristics of the powder, which also showed a broader size range compared to the SFTR powder.

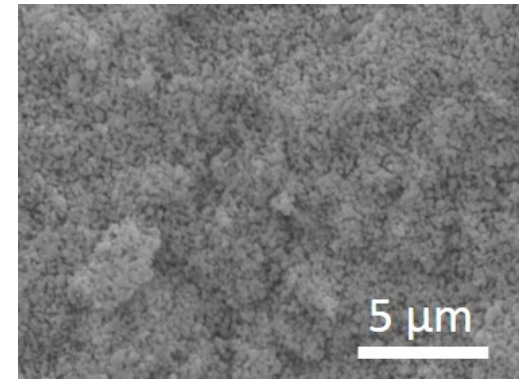

(a)

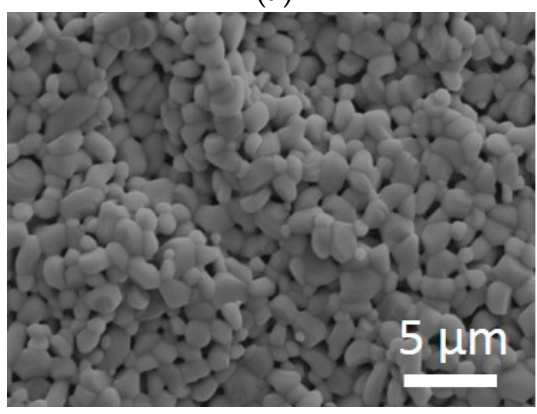

(c)

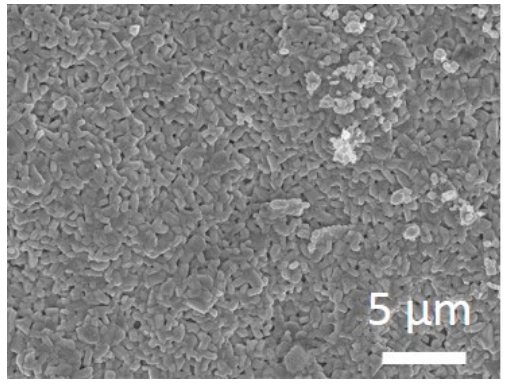

(b)

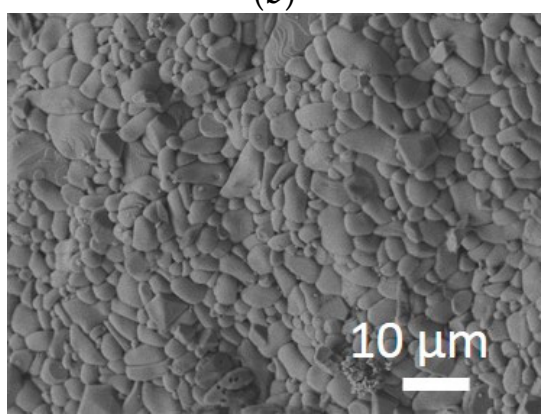

(d)

Figure 7. Cont. 


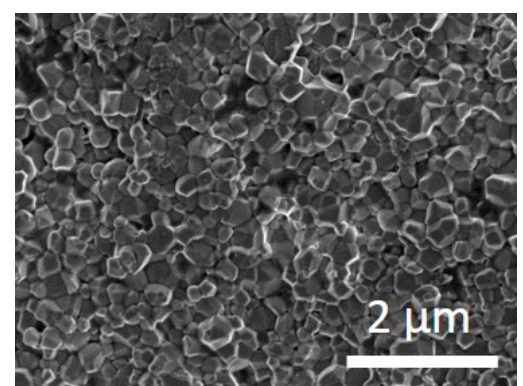

(e)

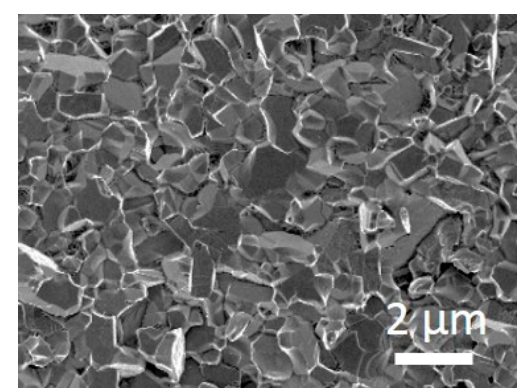

(f)

Figure 7. SEM micrographs of fractured ZnO samples after sintering (a) SFTR nanopowder sintered naturally at $900{ }^{\circ} \mathrm{C}$ for $2 \mathrm{~h}$, (b) Nabond nanopowder sintered naturally at $900{ }^{\circ} \mathrm{C}$ for $2 \mathrm{~h}$, (c) SFTR nanopowder sintered naturally at $1100{ }^{\circ} \mathrm{C}$ for $2 \mathrm{~h}$, (d) Nabond nanopowder sintered naturally at $1100{ }^{\circ} \mathrm{C}$ for $2 \mathrm{~h}$, (e) SFTR nanopowder sintered by SPS at $900{ }^{\circ} \mathrm{C} 5 \mathrm{~min}$, (f) Nabond nanopowder sintered by SPS at $900{ }^{\circ} \mathrm{C}$ for $5 \mathrm{~min}$.

\section{Discussion}

Despite their evident qualities and potentialities for multiple applications, ceramic nanopowders have to deal with two major difficulties: their limited production on the market because of insufficient developments in nanopowders synthesis processes, and their reactivity in temperature leading to grain growth, which destroys their "nano" properties. $\mathrm{ZnO}$ nanopowder was synthesized with the Segmented Flow Tubular Reactor (SFTR), which produces a high powder quality and is reproducible. The precipitated powder was finer, $\mathrm{dv}_{50} \sim 60 \mathrm{~nm}$, compared to $\sim 250 \mathrm{~nm}$ for a commercial powder, with a narrower particle size distribution, a lower degree of agglomeration (whereas the commercial powder had to be pre-milled by attrition to remove a tail of agglomerates) and a higher specific surface area. The sinterability of ZnO nanopowder synthesized by the SFTR was then studied, by natural sintering at $900^{\circ} \mathrm{C}$ and $1100^{\circ} \mathrm{C}$, and Spark Plasma Sintering (SPS) at $900^{\circ} \mathrm{C}$ and $100 \mathrm{MPa}$. The samples could not be densified at low temperature by conventional sintering, but SPS led to a fully dense material after only $5 \mathrm{~min}$ at $900{ }^{\circ} \mathrm{C}$, while also limiting the grain growth to a factor of four, leading to a mean grain size of $0.24 \mu \mathrm{m} \pm 0.08 \mu \mathrm{m}$, and a regular morphology. The same process was applied to a commercial nanopowder. Despite its high quality, it was necessary to add an attrition step to eliminate the presence of agglomerates. The SPS sintering was also efficient in limiting the grain growth and conserving fine microstructure. Nevertheless, the mean grain size of this $\mathrm{ZnO}$ nanopowder was higher than the SFTR synthesis and led to a higher grain size. In conclusion, the finer SFTR powder with a narrower size distribution gave a finer grain size with a narrower grain size distribution after sintering with SPS. This study illustrates that SPS can sinter to high densities and limit grain growth, irrespective of the starting powder, but to obtain nanostructured ceramic materials, one needs to combine high-quality nanopowder synthesis processes with ultra-fast sintering techniques such as SPS.

Acknowledgments: The authors thank the Swiss cost office, COST Action 539, for financial support.

Author Contributions: Anne Aimable and Paul Bowen conceived and designed the experiments; Anne Aimable characterized the powders, analyzed the data and wrote the paper; Michael Stuer and Zhe Zhao conducted SPS experiments; Hervé Goure Doubi conducted natural sintering experiments.

Conflicts of Interest: The authors declare no conflict of interest. The founding sponsors had no role in the design of the study; in the collection, analyses, or interpretation of data; in the writing of the manuscript, and in the decision to publish the results.

\section{References}

1. Lange, F.F. Powder Processing Science and Technology for Increased Reliability. J. Am. Ceram. Soc. 1989, 72, 3-15. [CrossRef] 
2. Verwey, E.J.W.; Overbeek, J.T.G.; Overbeek, J.T.G. Theory of the stability of lyophobic colloids. In Courier Corporation; Dover Publications: Mineola, NY, USA, 1999.

3. Lewis, J.A. Colloidal Processing of Ceramics. J. Am. Ceram. Soc. 2000, 83, 2341-2359. [CrossRef]

4. Bergstrom, L. Colloidal Processing of Ceramics. Available online: https://fr.scribd.com/document/ 259254918/Colloidal-Processing-of-Ceramics (accessed on 16 December 2016).

5. Cameron, C.P.; Raj, R. Grain-Growth Transition During Sintering of Colloidally Prepared Alumina Powder Compacts. J. Am. Ceram. Soc. 1988, 71, 1031-1035. [CrossRef]

6. Wang, Z.L. Zinc oxide nanostructures: Growth, properties and applications. J. Phys. Condens. Matter 2004, 16, R829-R858. [CrossRef]

7. Ozgur, U.; Alivov, Y.I.; Liu, C.; Teke, A.; Reshchikov, M.A.; Dogan, S.; Avrutin, V.; Cho, S.-J.; Morkoc, H. A comprehensive review of $\mathrm{ZnO}$ materials and devices. J. Appl. Phys. 2005, 98, 11. [CrossRef]

8. Clarke, D.R. Varistor Ceramics. J. Am. Ceram. Soc. 1999, 82, 485-502. [CrossRef]

9. Fonoberov, V.A.; Balandin, A.A. ZnO Quantum Dots: Physical Properties and Optoelectronic Applications. J. Nanoelectron. Optoelectron. 2006, 1, 19-38. [CrossRef]

10. Willander, M.; Nur, O.; Zhao, Q.X.; Yang, L.L.; Lorenz, M.; Cao, B.Q.; Pérez, J.Z.; Czekalla, C.; Zimmermann, G.; Grundmann, M.; et al. Zinc oxide nanorod based photonic devices: Recent progress in growth, light emitting diodes and lasers. Nanotechnology 2009, 20, 332001. [CrossRef] [PubMed]

11. Bueno, P.R.; Varela, J.A.; Longo, E. $\mathrm{SnO}_{2}, \mathrm{ZnO}$ and related polycrystalline compound semiconductors: An overview and review on the voltage-dependent resistance (non-ohmic) feature. J. Eur. Ceram. Soc. 2008, 28, 505-529. [CrossRef]

12. Norris, L.F.; Parravano, G. Sintering of Zinc Oxide. J. Am. Ceram. Soc. 1963, 46, 449-452. [CrossRef]

13. Nicholson, G.C. Grain Growth in Zinc Oxide. J. Am. Ceram. Soc. 1965, 48, 214-215. [CrossRef]

14. Gupta, T.K.; Coble, R.L. Sintering of ZnO: I Densification and Grain Growth. J. Am. Ceram. Soc. 1968, 51, 521-525. [CrossRef]

15. Senda, T.; Bradt, R.C. Grain Growth in Sintered ZnO and ZnO-Bi2O3 Ceramics. J. Am. Ceram. Soc. 1990, 73, 106-114. [CrossRef]

16. Pillai, S.C.; Kelly, J.M.; McCormack, D.E.; Ramesh, R. High performance ZnO varistors prepared from nanocrystalline precursors for miniaturised electronic devices. J. Mater. Chem. 2008, 18, 3926-3932. [CrossRef]

17. Nahm, C.-W. Low-temperature sintering effect on varistor properties of $\mathrm{ZnO}-\mathrm{V}_{2} \mathrm{O}_{5}-\mathrm{MnO}_{2}-\mathrm{Nb}_{2} \mathrm{O}_{5}-\mathrm{Bi}_{2} \mathrm{O}_{3}$ ceramics. Ceram. Int. 2013, 39, 2117-2121. [CrossRef]

18. Shahraki, M.M.; Shojaee, S.A.; Sani, M.A.F.; Nemati, A.; Safaee, I. Two-step sintering of ZnO varistors. Solid State Ion. 2011, 190, 99-105. [CrossRef]

19. Anselmi-Tamburini, U.; Garay, J.E.; Munir, Z.A. Fast low-temperature consolidation of bulk nanometric ceramic materials. Scr. Mater. 2006, 54, 823-828. [CrossRef]

20. Nygren, M.; Shen, Z. Hot Pressing and Spark Plasma Sintering. In Ceramics Science and Technology; Riedel, R., Chen, I.-W., Eds.; Wiley-VCH Verlag GmbH \& Co. KGaA: Berlin, Germany, 2011; pp. 189-214.

21. Anselmi-Tamburini, U.; Gennari, S.; Garay, J.E.; Munir, Z.A. Fundamental investigations on the spark plasma sintering/synthesis process: II. Modeling of current and temperature distributions. Mater. Sci. Eng. A 2005, 394, 139-148. [CrossRef]

22. Munir, Z.A.; Anselmi-Tamburini, U.; Ohyanagi, M. The effect of electric field and pressure on the synthesis and consolidation of materials: A review of the spark plasma sintering method. J. Mater. Sci. 2006, 41, 763-777. [CrossRef]

23. Munir, Z.A.; Quach, D.V.; Ohyanagi, M. Electric current activation of sintering: A review of the pulsed electric current sintering process. J. Am. Ceram. Soc. 2011, 94, 1-19. [CrossRef]

24. Okamoto, M.; Akimune, Y.; Furuya, K.; Hatano, M.; Yamanaka, M.; Uchiyama, M. Phase transition and electrical conductivity of scandia-stabilized zirconia prepared by spark plasma sintering process. Solid State Ion. 2005, 176, 675-680. [CrossRef]

25. Gao, L.; Li, Q.; Luan, W.; Kawaoka, H.; Sekino, T.; Niihara, K. Preparation and Electric Properties of Dense Nanocrystalline Zinc Oxide Ceramics. J. Am. Ceram. Soc. 2002, 85, 1016-1018. [CrossRef]

26. Cha, S.I.; Hong, S.H.; Kim, B.K. Spark plasma sintering behavior of nanocrystalline WC-10Co cemented carbide powders. Mater. Sci. Eng. A 2003, 351, 31-38. [CrossRef] 
27. Watari, F.; Yokoyama, A.; Omori, M.; Hirai, T.; Kondo, H.; Uo, M.; Kawasaki, T. Biocompatibility of materials and development to functionally graded implant for bio-medical application. Compos. Sci. Technol. 2004, 64, 893-908. [CrossRef]

28. Gu, Y.W.; Loh, N.H.; Khor, K.A.; Tor, S.B.; Cheang, P. Spark plasma sintering of hydroxyapatite powders. Biomaterials 2002, 23, 37-43. [CrossRef]

29. Ma, N.; Li, J.-F.; Zhang, B.P.; Lin, Y.H.; Ren, L.R.; Chen, G.F. Microstructure and thermoelectric properties of $\mathrm{Zn}_{1-\mathrm{x}} \mathrm{Al}_{\mathrm{x}} \mathrm{O}$ ceramics fabricated by spark plasma sintering. J. Phys. Chem. Solids 2010, 71, 1344-1349. [CrossRef]

30. Stuer, M.; Zhao, Z.; Aschauer, U.; Bowen, P. Transparent polycrystalline alumina using spark plasma sintering: Effect of Mg, Y and La doping. J. Eur. Ceram. Soc. 2010, 30, 1335-1343. [CrossRef]

31. Beynet, Y.; Izoulet, A.; Guillemet-Fritsch, S.; Chevallier, G.; Bley, V.; Pérel, T.; Malpiece, F.; Morel, J.; Estournès, C. ZnO-based varistors prepared by spark plasma sintering. J. Eur. Ceram. Soc. 2015, 35, 1199-1208. [CrossRef]

32. Lin, D.; Fan, L.; Shi, Y.; Xie, J.; Lei, F.; Ren, D. Elaboration of translucent ZnO ceramics by spark plasma sintering under low temperature. Opt. Mater. (n.d.) 2016. [CrossRef]

33. Vacassy, R.; Jongen, N.; Bowen, P.; Lemaître, J.; Hofmann, H. Development of the new segmented flow tubular reactor for powder technology. Proc. World Congr. Part. Technol. 1998, 3, 196-197.

34. Lemaitre, J.; Jongen, N.; Vacassy, R.; Bowen, P. Production of Powders. United States Patent 6458335, 1 October 2002.

35. Vacassy, R.; Lemaitre, J.; Hofmann, H.; Gerlings, J.H. Calcium carbonate precipitation using new segmented flow tubular reactor. AIChE J. 2000, 46, 1241-1252. [CrossRef]

36. Bowen, P.; Donnet, M.; Testino, A.; Viviani, M.; Buscaglia, M.T.; Buscaglia, V.; Nanni, P. Synthesis of Barium Titanate Powders by Low-Temperature Aqueous Synthesis Using a New Segmented Flow Tubular Reactor. Key Eng. Mater. 2002, 206, 21-24. [CrossRef]

37. Guillemet-Fritsch, S.; Aoun-Habbache, M.; Sarrias, J.; Rousset, A.; Jongen, N.; Donnet, M.; Bowen, P.; Lemaitre, J. High-quality nickel manganese oxalate powders synthesized in a new segmented flow tubular reactor. Solid State Ion. 2004, 171, 135-140. [CrossRef]

38. Donnet, M.; Jongen, N.; Lemaître, J.; Bowen, P. New morphology of calcium oxalate trihydrate precipitated in a segmented flow tubular reactor. J. Mater. Sci. Lett. 2000, 19, 749-750. [CrossRef]

39. Jongen, N.; Donnet, M.; Bowen, P.; Lemaitre, J.; Hofmann, H.; Schenk, R.; Hofmann, C.; Aoun-Habbache, M.; Guillemet-Fritsch, S.; Sarrias, J. Development of a Continuous Segmented Flow Tubular Reactor and the Scale-out Concept-In Search of Perfect Powders. Chem. Eng. Technol. 2003, 26, 303-305. [CrossRef]

40. Bowen, P.; Testino, A.; Legagneur, V.; Donnet, M.; Hofmann, H.; Cobut, N. Proceedings of the Fifth World Congress on Particle Technology (WCPT5), Orlando, FL, USA, 23 April 2006.

41. Aimable, A.; Jongen, N.; Testino, A.; Donnet, M.; Lemaître, J.; Hofmann, H.; Bowen, P. Precipitation of Nanosized and Nanostructured Powders: Process Intensification and Scale-Out Using a Segmented Flow Tubular Reactor (SFTR). Chem. Eng. Technol. 2011, 34, 344-352. [CrossRef]

42. Aimable, A.; Strachowski, T.; Wolska, E.; Lojkowski, W.; Bowen, P. Comparison of two innovative precipitation systems for $\mathrm{ZnO}$ and $\mathrm{Al}$-doped $\mathrm{ZnO}$ nanoparticle synthesis. Process. Appl. Ceram. 2010, 4, 107-114. [CrossRef]

43. Aimable, A.; Buscaglia, M.T.; Buscaglia, V.; Bowen, P. Polymer-assisted precipitation of ZnO nanoparticles with narrow particle size distribution. J. Eur. Ceram. Soc. 2010, 30, 591-598. [CrossRef]

44. Langford, J.I.; Wilson, A.J.C. Scherrer after sixty years: A survey and some new results in the determination of crystallite size. J. Appl. Crystallogr. 1978, 11, 102-113. [CrossRef]

45. Aimable, A.; Bowen, P. Nanopowder metrology and nanoparticle size measurement-Towards the development and testing of protocols. Process. Appl. Ceram. 2010, 4, 157-166. [CrossRef]

(C) 2017 by the authors. Licensee MDPI, Basel, Switzerland. This article is an open access article distributed under the terms and conditions of the Creative Commons Attribution (CC BY) license (http:// creativecommons.org/licenses/by/4.0/). 